\title{
Doctors as patients: Historical perspectives on the challenge of personal illness among practising physicians
}

\author{
Jonatan Wistrand* \\ Faculty of Medicine, Department of Medical History, Lund University, Sweden
}

\section{Commentary}

Recent years have seen the publication of several new books about doctors' personal experiences of serious illness. Paul Kalanithi's When Breath Becomes Air (2016), Rana Awdish's In Shock (2017), and Caroline Elton's Also Human: The Inner Lives of Doctors (2018) set out for readers the particular kinds of problems that await a doctor as he or she falls ill [1-3]. In addition to the expected physical and mental constraints, these doctors found that ill health often entails a derailment of their professional identity. Still at their place of work but now dressed differently, lying in bed rather than standing beside it. The three books and others have been hailed as part of a new narrative trend in health care, focusing attention on the complex plight of the medical profession, and inviting readers to look beyond the stereotypes of the traditional doctor to see a more complex and fragile individual. However, a glance back at history suggests that this is not the entire truth. On the contrary, interest in the ailing physicians and their narratives, as well as possible correlations between their working conditions and state of health, dates far back in time, although expressed in different ways over the years.

Scholarly attempts to examine the health status and help-seeking behaviour of physicians can be traced as far back as to the second half of the nineteenth century. In the early studies, one diagnosis in particular was addressed, namely addiction. The advent of the hypodermic syringe in mid nineteenth century and a blithe underestimation of the addictive power of intravenous morphine then saw a veritable epidemic of morphinism among medical practitioners. In 1883 the American doctor J B Mattison warned that in a certain New England city, containing upward of one hundred medical men, between thirty and forty are addicted to some form of opium' [4]. Another condition that attracted scholarly attention at the turn of the twentieth century was angina pectoris. The Canadian physician, Sir William Osler, described it in The Lancet in 1910 as a morbus medicorum-a disease doctors were especially prone to [5]. The notion that angina pectoris was a doctors' disease held good until at least the 1940s. Having compared the incidence of coronary sclerosis among 'physicians, bankers, lawyers, clergymen, labourers, and farmers among the clientele of the Mayo Clinic', the cardiologist Harry L. Smith concluded in 1937 that levels were 'highest of all among physicians' [6]. Interestingly, stress was singled out as the reason why doctors were overrepresented for both addiction and heart disease. Similarly, 'occupational strain' was said to be the reason for the high levels of suicide among doctors as early as the 1920s [7]. And still today, work-related mental stress is described as the leading cause of physician burnout, the epidemic of our time [8].

In addition to these scholarly attempts to estimate the incidence and prevalence of various stress-related diseases, doctors' personal experiences of illness have also been the subject of several twentiethcentury anthologies. The first was Ärzte als Patienten (1929), edited by Alfred Grotjahn [9]. An impressive volume with 138 autobiographical notes on illness, including the editor's own description of repeated attacks of cholelithiasis.

Ärzte als Patienten not only gives a fascinating insight into doctors' views on their illnesses, but for the modern reader is also a historical illustration of how the concept of disease vary over time, with narratives concerning Hysterie, Geiststörung, and Homosexualität. Grotjahn's book received considerable international attention [10], and later inspired to the American anthology When doctors are patients (1952), edited by Max Pinner and Benjamin Miller [11]. Like Ärzte als Patienten, its American sequel is also a revealing account of how doctors have reacted to a number of conditions, with chapters ranging from Manic-Depressive Psychosis and Weather Sensitiveness to Typhus Fever in Auschwitz Concentration Camp.

In order to properly assess such narratives, it is essential to know what instructions the editors gave their authors. This is spelt out in both anthologies, as well as in the more recent When doctors get sick (1987), edited by Harvey Mandell and Howard Spiro [12]. The main purpose of all three anthologies seems to have been educational, but with different readerships in mind. While Pinner and Miller in the 1950s suggest their book would be useful for the non-medical reader since doctors are 'able to make new adjustments that would not be possible for the average patient'(p.xvii), Mandell and Spiro in the 1980s specifically address the medical reader: 'Since every physician cannot have every disease ... we thought physicians might benefit, if not prosper, from the illnesses of their colleagues'(p.xii). Another difference is that When doctors get sick (1987), unlike the two earlier anthologies, focuses on the contributors' difficulties in coming to terms with their dual identity as both doctor and patient: 'The physician trying to remain in control of his own care forgets the clouded judgement of the sick and how wrong their choices may be.' (p.454). Where doctors in the 1920s and 1950s were regarded as informed and intellectual representatives of illness experience, by the 1980s they are viewed as confused victims of two incongruent identities - one professional and one private.

An interesting question is why the dilemma of the sick doctor is treated so differently in the three anthologies? Is it because doctors

${ }^{*}$ Correspondence to: Jonatan Wistrand, Faculty of Medicine, Department of Medical History, Lund University, Sweden, Tel: 0046-(0)703187239; E-mail: jonatan.wistrand@med.lu.se

Key words: medical history, narrative medicine

Received: July 17, 2020; Accepted: July 22, 2020; Published: July 27, 2020 
in the first half of twentieth century did not experience falling ill as a dilemma, secure as they were in their professional identity throughout their illness? Or was it that the difficulties they faced were, on the contrary, too stigmatised to discuss publicly? As is often the case, each fresh perspective brings its own questions.

Clearly, illness experience among doctors has for a long time attracted the attention of both academic scholars and practising physicians. While books by the likes of Kalanithi, Awdish, and Elton naturally speak to us with the voice of actuality, the historical sources are also worth exploring. Not only do they bring insights into how medical practitioners over time have managed or failed to integrate their professional identity as a doctor with that as a patient, but they also hold up a mirror to the past, nuancing our understanding of the difficulties experienced by 'doctor-patients' today. In order to offer the correct care to this complex group of patients when we meet them in our daily clinic, the historical narratives by sick doctors deserve to be read in parallel with their contemporary counterparts.

\section{Author's contributions}

The author is the sole contributor to the submitted article, including literature search, study design, data interpretation, and writing.

\section{Conflict of interest statement}

The author declares no conflicts of interest.

\section{Role of funding source}

The study was funded by 'Greta och Johan Kocks stiftelse'.

\section{Ethics committee approval}

The article has not been subject to consideration of ethical committee.

\section{References}

1. Kalanithi P (2016) When Breath Becomes Air. New York: Random House.

2. Awdish R (2017) In Shock. New York: St Martin's Press.

3. Elton C (2018) Also Human: The Inner Lives of Doctors. New York: Basic Books.

4. Mattison JB (1883) Opium Addiction Among Medical Men. Med Rec 23: 621-623.

5. Osler W (1910) The Lumleian Lectures on Angina Pectoris. Lancet 175: 697-702.

6. Smith H (1937) Incidence of Coronary Sclerosis Among Physicians as Compared With Members of Other Occupations. JAMA 108: 1327-1329.

7. Marchalik D (2019) Physician burnout in the modern era. Lancet 393: 868-869.

8. Grinspoon P (2018) Physician burnout can affect your health. Harvard Health Blog.

9. Grotjahn A (ed.) (1929) Ärzte als Patienten: Subjektive Krankengeschichten in ärztlichen Selbstschilderungen. Leipzig: George Thieme Verlag.

10. Aerzte als Patienten (1929) Subjektive Krankengeschichten in ärztlichen Selbstschilderungen. JAMA 93: 2045-2046.

11. Pinner M, Miller B (eds.) (1952) When doctors are patients. New York: Norton.

12. Mandell H, Spiro H (eds.) (1987) When doctors get sick. New York: Plenum Medical.

Copyright: $\odot 2020$ Wistrand J. This is an open-access article distributed under the terms of the Creative Commons Attribution License, which permits unrestricted use, distribution, and reproduction in any medium, provided the original author and source are credited. 